\title{
Human Rights Impact Assessment of Business Activities: Key Criteria for Establishing a Meaningful Practice
}

\author{
Nora GÖTZMANN*
}

\begin{abstract}
This article considers the emerging practice of human rights impact assessment (HRIA) in the field of business and human rights. As HRIA is relatively new, current approaches vary considerably, indicating that there is a need for the business and human rights community to engage in further dialogue and debate about what good practice HRIA can and should entail. I propose five key criteria for HRIA of business activities: (1) applying international human rights standards; (2) considering the full scope of impacts; (3) adopting a human rights-based process; (4) ensuring accountability; and (5) addressing impacts according to severity. It is suggested that these criteria should form the basis of methodologies used to assess human rights impacts of business activities, with the view to developing HRIA practice that meaningfully contributes to preventing and addressing adverse impacts of business activities on the human rights enjoyment of workers and communities.
\end{abstract}

Keywords: corporate social responsibility, due diligence, Guiding Principles on Business and Human Rights, human rights-based approach

\section{INTRODUCTION}

In this article I consider the emerging practice of human rights impact assessment (HRIA) in the field of business and human rights (BHR). With increased attention being given to the accountability of businesses for their human rights impacts, in part due to the United Nations Guiding Principles on Business and Human Rights (UNGPs), ${ }^{1}$ HRIA has gained traction as one of the tools available to business enterprises, non-government organizations (NGOs), governments and other stakeholders to assess the impacts of

\footnotetext{
* The Danish Institute for Human Rights; Centre for Social Responsibility in Mining, The University of Queensland. This article is based on a working paper entitled 'Human Rights and Impact Assessment: Conceptual and Practical Considerations in the Private Sector Context', Matters of Concern Human Rights Research Paper No. 2014/2 (Copenhagen: Danish Institute for Human Rights, 2014). I would like to thank Stéphanie Lagoutte, Frank Seier and Frank Vanclay for their helpful comments on earlier drafts. I would also like to thank Roya Høvsgaard and Jacqueline Tedaldi for their research assistance.

1 Human Rights Council, 'Guiding Principles on Business and Human Rights: Implementing the United Nations "Protect, Respect and Remedy" Framework', A/HRC/17/31 (21 March 2011) (UNGPs). See also Human Rights Council, 'Human Rights Impact Assessments - Resolving Key Methodological Questions', A/HRC/4/74 (5 February 2007).
} 
business activities on the human rights enjoyment of workers and community members. The UNGPs, which were unanimously endorsed by the United Nations Human Rights Council in $2011,{ }^{2}$ articulate the expectation that businesses should respect human rights by using a process of due diligence - that is, a process by which to identify, prevent, mitigate and account for how a business addresses the adverse human rights impacts with which it is involved. The assessment of human rights impacts is a critical step in this process. ${ }^{3}$ Whilst the UNGPs set out the expectation that businesses should assess their human rights impacts, they do not specify precisely how this should be done, nor what essential features might be required for such an assessment to ensure that it is not only consistent with international human rights standards and principles but also contributes to enhancing the accountability of businesses for preventing and addressing their adverse human rights impacts on workers and communities.

Compared to the more established fields of environmental impact assessment (EIA) ${ }^{4}$ and social impact assessment (SIA), ${ }^{5}$ HRIA is an emerging practice. Correspondingly, guidance and literature on HRIA, as well as public domain examples of actual assessments that have been undertaken, are somewhat sparse. ${ }^{6}$ There is also limited scholarly literature on HRIA, in the BHR context, that usefully reflects on current approaches and could inform the developing practice. ${ }^{7}$ Nevertheless, from a review of the sources that are available, it can be observed that emerging HRIA approaches in the BHR field vary considerably. Moreover, the extent to which such assessments actually facilitate processes and outcomes that effectively address the adverse human rights impacts of business activities remains largely unknown. ${ }^{8}$ Such an amorphousness can be problematic from the perspective of impact assessment practitioners, rights-holders and businesses, as this hinders the development of a common understanding of what 'good practice' HRIA can and should entail. Arguably, there is a strong need for the BHR community to engage in further dialogue and debate about HRIA practice and the role of HRIA in the BHR discourse. Without the development of such 'shared normative understandings of what the HRIA process should represent, there is a danger that the

\footnotetext{
2 Human Rights Council, 'Human Rights and Transnational Corporations and Other Business Enterprises', A/HRC/ RES/17/4 (6 July 2011).

3 UNGPs, note 1, Principles 15 and 17.

4 'The process of identifying, predicting, evaluating and mitigating the biophysical, social, and other relevant effects of development proposals prior to major decisions being taken and commitments made.' International Association for Impact Assessment, Principles of Environmental Impact Assessment Best Practice (Fargo: International Association for Impact Assessment, 1999). See also Richard K Morgan, 'Environmental Impact Assessment: The State of the Art' (2012) 30:1 Impact Assessment and Project Appraisal 5.

5 'Social impact assessment includes the processes of analysis, monitoring and managing the intended and unintended social consequences, both positive and negative, of planned interventions (policies, programs, plans, projects) and any social change processes invoked by those interventions. Its primary purpose is to bring about a more sustainable and equitable biophysical and human environment.' Frank Vanclay, 'International Principles for Social Impact Assessment' (2003) 21:1 Impact Assessment and Project Appraisal 5, 6. See also Ana Maria Esteves et al, 'Social Impact Assessment: The State of the Art' (2012) 30:1 Impact Assessment and Project Appraisal 34; Frank Vanclay et al, Social Impact Assessment: Guidance for Assessing and Managing the Social Impacts of Projects (Fargo: International Association for Impact Assessment, 2015).

6 Existing literature and guidance on HRIA are elaborated in Section III.

7 Notable exceptions include writing by James Harrison and Simon Walker, and the articles published in volume 31:2 of the Impact Assessment and Project Appraisal. These are discussed further in Section III.

8 For example, I am not aware of any empirical studies that have been conducted to systematically evaluate the effectiveness of site- or project-level HRIAs of business activities.
} 
nomenclature will lose its status as representing a robust evidence-based process of assessing impacts'?

In this article, I propose five key criteria for the assessment of human rights impacts of business activities: (1) applying international human rights standards; (2) considering the full scope of impacts; (3) adopting a human rights-based process; (4) ensuring accountability; and (5) addressing impacts according to severity. ${ }^{10}$ These criteria can be derived from key literature and guidance in the area of HRIA, in particular literature elaborating the 'essential' or 'original' elements of HRIA, the human rights-based approach and the UNGPs. I argue that these criteria provide useful parameters to guide the development, implementation and evaluation of the evolving HRIA methodologies and practice, to ensure that both the content and process of assessments are consistent with international human rights standards and principles and the expectations set out in the UNGPs. I posit that such consistency increases the likelihood of HRIA to contribute meaningfully to preventing and addressing adverse business-related human rights impacts.

After providing a brief overview of emerging HRIA approaches in the BHR context, I address each of the five criteria in turn, discussing the reasoning for its inclusion and what it entails, as well as reflecting on some of the challenges that may be encountered by BHR practitioners in the implementation of HRIA. I conclude with reflections on how the five criteria might inform a future research agenda that enquires into the effectiveness of HRIA and its ability (or lack thereof) to contribute to enhancing the accountability of businesses for addressing their adverse human rights impacts on workers and communities.

\section{Human Rights Impact Assessment as an Emerging Practice}

EIA, and to a lesser but nevertheless significant degree SIA, are now a standard part of due diligence in many business contexts, in particular large-scale projects such as mines, oil and gas projects, dams and large infrastructure developments. ${ }^{11}$ Frequently, companies implementing such projects assess environmental and social impacts using a combined Environmental, Social and Health Impact Assessment (ESHIA). In many jurisdictions, EIA is required by law as part of the project approval process. In some cases, they include social dimensions, either directly or indirectly, although regulatory requirements for the explicit inclusion of social impacts, or conducting SIA, remain limited. $^{12}$ Companies undertake EIA and SIA for a range of reasons, including

\footnotetext{
9 James Harrison, 'Establishing a Meaningful Human Rights Due Diligence Process for Corporations: Learning From Experience of Human Rights Impact Assessment' (2013) 31:2 Impact Assessment and Project Appraisal $107,115$.

10 I have previously addressed these five criteria in a working paper: Nora Götzmann, 'Human Rights and Impact Assessment: Conceptual and Practical Considerations in the Private Sector Context', Matters of Concern Human Rights Research Paper No. 2014/2 (Copenhagen: Danish Institute for Human Rights, 2014), http://www.humanrights.dk/ publications/human-rights-impact-assessment (accessed 17 August 2016). A further sub-division of the criteria for more practice-oriented purposes is elaborated in Nora Götzmann et al, Human Rights Impact Assessment Guidance and Toolbox (Copenhagen: Danish Institute for Human Rights, 2016).

11 See, e.g., Esteves et al, note 5; Morgan, note 4.

12 Frank Vanclay, 'Developments in Social Impact Assessment: An Introduction to a Collection of Seminal Research Papers' in Frank Vanclay (ed.), Developments in Social Impact Assessment (Cheltenham: Edward Elgar, 2014) xv.
} 
regulatory requirements, as part of complying with company standards, as well as to meet or respond to social expectations. It is now generally acknowledged that EIA and SIA do not simply perform the role of ensuring regulatory approval but that they are key corporate risk and impact management tools. ${ }^{13}$

Compared to EIA and SIA, the field of HRIA is relatively new, which is also reflected in the limited scholarly literature on the topic. ${ }^{14}$ HRIA has been defined as 'an instrument for examining policies, legislation, programs and projects and identifying and measuring their effects on human rights'. ${ }^{15}$ Within emerging practice, several strands of HRIA have been identified, including the areas of development, the right to health, children's rights, business activities, international trade and investment, and impact assessments conducted for public authorities. ${ }^{16}$ It is worth noting that within and between these strands, the focus is diverse in terms of the rights-holders and duty-bearers involved, the level of detail in the methodologies and analysis, and the precise purpose and intent of the assessments. ${ }^{17}$ For example, in the case of HRIA conducted for government programmes, the focus might be on establishing whether a certain human rights-focused intervention is meeting its objectives in terms of improving the realization of the particular human right(s) in question, such as an analysis of whether a government equal opportunities programme is effective in generating more employment opportunities for target groups such as women or ethnic minorities. ${ }^{18}$ In the BHR context, on the other hand, the focus to date has primarily been on identifying, usually through ex-post assessments, the adverse impacts of business activities on the human rights enjoyment of workers and community members. ${ }^{19}$

With regard to business activities, the UNGPs articulate the expectation that businesses should respect human rights by using a process of due diligence, in which the assessment of human rights impacts is a critical step. ${ }^{20}$ It is important to appreciate that the UNGPs expect businesses to identify and assess their human rights impacts, not necessarily to conduct HRIA per se. Thus, whilst stand-alone HRIA (i.e., assessment that focuses exclusively on human rights impacts) may be one approach taken, the UNPGs do not foresee this as the only approach, indicating that the assessment of human rights impacts may also be incorporated within other appropriate processes (e.g., ESHIA), as long as the focus on human rights is comprehensive. ${ }^{21}$ Furthermore, whilst the UNGPs provide some basic parameters for assessing human rights impacts, they do not provide an elaborated methodology for doing so. ${ }^{22}$ Arguably, this is only logical given that the

\footnotetext{
13 See, e.g., Esteves et al, note 5, 36; Morgan, note 4, 8; Vanclay et al, note 5, 6.

14 See note 7 and Section III.

15 World Bank and Nordic Trust Fund, Human Rights Impact Assessments: A Review of the Literature, Differences with other forms of Assessments and Relevance for Development (Washington: World Bank and Nordic Trust Fund, 2013) 1.

16 See, e.g., James Harrison, 'Measuring Human Rights: Reflections on the Practice of Human Rights Impact Assessment and Lessons for the Future', Legal Studies Research Paper 26/2010, University of Warwick School of Law, http://ssrn.com/abstract=1706742 (accessed 17 August 2016).

17 Ibid; World Bank and Nordic Trust Fund, note 15, 8.

18 Ibid.

19 Ibid. See also the HRIA assessments referred to in note 40.

20 UNGPs, note 1, Principles 15, 17 and 18.

21 Ibid, Principle 18 commentary.

22 Ibid.
} 
UNGPs provide overall guidance on BHR, rather than purporting to constitute a detailed methodological approach for how each individual aspect should be addressed. However, it does also indicate a need for the subsequent elaboration of what precisely the methodologies and practices for assessing human rights impacts should entail in the context of business activities.

The emerging practice of HRIA in the BHR field presents a diverse range of approaches. For instance, there are examples of stand-alone HRIAs, ${ }^{23}$ as well as approaches that seek to integrate human rights into ESHIA. ${ }^{24}$ In terms of the focus, stakeholders involved and depth of analysis, current practice appears to include within the category of HRIA anything ranging from a short desk-top review to multi-month investigative processes involving numerous stakeholders and topics of analysis. At a more theoretical level, there are few examples of scholarly literature that elaborate a HRIA framework for business activities, or evaluate the effectiveness of current approaches. ${ }^{25}$

In this article, I focus on the first of these aspects, by elaborating what content and process elements should be considered essential for HRIA of business activities to ensure that such assessments are aligned with international human rights standards and principles as well as with the expectations set out in the UNGPs. I will use the term 'HRIA' to include both stand-alone assessments (i.e., assessments that focus exclusively on human rights) and integrated assessments (i.e., assessments that integrate human rights into EIA, SIA or ESHIA) conducted on a consultancy basis for business activities at the project- or site-level (i.e., the mine-site, liquefied natural gas plant, factory and so forth). Integrated assessments have been included for the purpose of this discussion because many businesses are adopting integrated approaches and therefore it is important to evaluate the adequacy of human rights coverage in such assessments. I treat such project-level assessments conducted for companies on a consultancy basis as distinct from other strands of HRIA, such as those conducted for government programmes, community-based processes, ${ }^{26}$ or sector-wide approaches. ${ }^{27}$ It may well be the case that the criteria proposed have relevance for these other strands of HRIA. However, this should not be presumed and would need to be further investigated as differences in the nature of the duty-bearer obligations, precise objectives of the assessment, and the stakeholders involved, will have implications for the approach to be taken. ${ }^{28}$ In the next section, I introduce and discuss the five key criteria proposed for the assessment of human rights impacts of business activities.

\footnotetext{
23 See note 40.

24 E.g., DIHR and IPIECA, Integrating Human Rights into Environmental, Social and Health Impact Assessments: A Practical Guide for the Oil and Gas Industry (Copenhagen: DIHR and IPIECA, 2013).

25 See Section III.

26 See, e.g., Oxfam America and Rights and Democracy, Community-based Human Rights Impact Assessments: Practical Lessons (Canada: Oxfam America and Rights and Democracy, 2010); Rights and Democracy, Human Rights Impact Assessments for Foreign Investment Projects: Learning from Community Experiences in the Philippines, Tibet, the Democratic Republic of Congo, Argentina and Peru (Montreal: Rights and Democracy, 2006); Gabrielle Watson et al, 'Human Rights Impact Assessment in Practice: Oxfam's Application of a Community-based Approach' (2013) 31:2 Impact Assessment and Project Appraisal 118.

27 E.g., Myanmar Centre for Responsible Business, Institute for Human Rights and Business and Danish Institute for Human Rights, Myanmar Oil \& Gas Sector Wide Impact Assessment (Yangon: MCRB, IHRB and DIHR, 2014).

28 See, e.g., James Harrison and Mary-Ann Stephenson, Human Rights Impact Assessment: Review of Practice and Guidance for Future Assessments (Edinburgh: Scottish Human Rights Commission, 2010) 37.
} 


\section{Key Criteria for the Assessment of Human Rights Impacts of Business Activities}

Despite the diversity, and at times divergence, in current HRIA approaches, it is possible to deduce several recurring elements in the literature and guidance. These elements reflect what is unique about HRIA, the value added, as well as emphasize those aspects which may to a lesser or greater degree be reflected in other impact assessment methodologies (e.g., EIA or SIA) but which arguably warrant heightened attention in the implementation of HRIA of business activities. This article brings together these essential elements into a set of criteria that can guide the further development, implementation and evaluation of HRIA methodologies and practice in the context of business activities at the project- or site- level. A key reference framework is of course the UNGPs. However, whilst the UNGPs outline a number of factors to be considered, how these might be applied in HRIA methodology and practice is not elaborated in detail. It is also worth recognizing that impact assessment theory and practice, including HRIA, predates the UNGPs and that therefore sources beyond the UNGPs need to be considered in elaborating what content and process elements should guide HRIA. In particular, literature elaborating the 'original' or 'essential' elements of HRIA and on the HRBA can provide valuable insights regarding the importance of focusing on both process and content in impact assessment, as well as providing elaboration of how factors such as non-discrimination, transparency and accountability might be reflected in HRIA processes. The following paragraphs provide a more detailed overview of the sources from which the five criteria are derived. For the purpose of introducing the sources I have grouped them into five categories, though there are of course some overlaps between them.

The sources in the first group focus on articulating the 'original' or 'essential' elements of HRIA. This includes scholarly literature that identifies and elaborates the elements of HRIA that distinguish it from other types of impact assessment. ${ }^{29}$ The 'essential' or 'original' elements of HRIA noted in these sources include: a link to the normative human rights framework; public participation; emphasis on equality and nondiscrimination; transparency and access to information; and a focus on accountability. ${ }^{30}$ Some sources also note that the precise content and process of HRIA may need to differ depending on the context; for example, whether the assessment analyses the human rights impacts of business activities, a public sector programme, or an investment agreement. ${ }^{31}$

These 'essential elements' can be mapped against the HRBA, the literature on which is a second key source for the analysis undertaken in this article. ${ }^{32}$ Although the HRBA

29 E.g., Harrison, note 9; Harrison, note 16; Simon Walker, The Future of Human Rights Impact Assessments of Trade Agreements (Antwerp: Intersentia, 2009); World Bank and Nordic Trust Fund, note 15.

30 E.g., World Bank and Nordic Trust Fund, note 15, 11-21.

31 Ibid, 8.

32 For an overview of the human rights-based approach see, e.g., International Human Rights Network et al, Human Rights-Based Approaches and European Union Development Aid Policies (Brussels: International Human Rights Network, 2008); Andrea Cornwall and Celestine Nyamu-Musembi, 'Putting the "Rights-Based Approach" to Development into Perspective' (2004) 25:8 Third World Quarterly 1415; Celestine Nyamu-Musembi and Andrea Cornwall, What is the "Rights-based Approach" All About? Perspectives from International Development Agencies, 
was developed in the field of international development cooperation, the importance of adopting a HRBA in the context of HRIA has been emphasized. ${ }^{33}$ According to the United Nations Stamford Common Understanding, the HRBA rests on three core components: (1) application of international human rights standards; (2) adherence to human rights principles, including using these to guide processes, e.g., equality and non-discrimination, participation and inclusion, accountability and the rule of law; and (3) emphasis on accountability, including through the analysis of the roles and capacities of rights-holders and duty-bearers. ${ }^{34}$ Essentially, a HRBA stresses that both process and outcomes of interventions should be compatible with international human rights standards and principles, including by recognizing individuals as agents in their own development, rather than as being merely subjects or beneficiaries of an intervention or programme. ${ }^{35}$

The UNGPs constitute the third resource. In addition to reflecting several of the HRBA components, ${ }^{36}$ Principle 18 outlines a number of additional aspects for the assessment of human rights impacts of business activities, namely: that both actual and potential adverse impacts must be identified and assessed; that the scope of the assessment should cover impacts that the business causes and contributes to, as well as impacts that are directly linked to its operations, products or services through business relationships; that human rights impacts are assessed according to their severity; that all human rights impacts are addressed; and that a prioritization of impacts is only relevant for the purpose of determining which mitigation measures to implement first in the event that not all impacts can be addressed simultaneously. ${ }^{37}$

The sources that outline the stages or steps of HRIA in the form of practical 'how to' guidance, or by summarizing such available guidance, provide a fourth group of resources. ${ }^{38}$ From such guides it can be inferred that HRIA should follow similar steps as

\section{(F'note continued)}

Institute of Development Studies Working Paper 234 (Brighton: IDS, 2004), http://www.ids.ac.uk/files/dmfile/Wp234.pdf (accessed 17 August 2016); Office of the United Nations High Commissioner for Human Rights (OHCHR), Frequently Asked Questions on a Human Rights-based Approach to Development Cooperation (New York and Geneva: UN, 2006).

33 See, e.g., Harrison, note 16, 5-6; Olga Lenzen and Maria d'Engelbronner, Guide to Corporate Human Rights Impact Assessment Tools (Utrecht Aim for Human Rights, 2009) 9; World Bank and Nordic Trust Fund, note 15, 11-20. For discussion of HRBA in SIA see, e.g., Gillian MacNaughton and Paul Hunt, 'A Human Rights-based Approach to Social Impact Assessment' in Frank Vanclay and Ana Maria Esteves (eds.), New Directions in Social Impact Assessment (Cheltenham: Edward Elgar, 2011) 355.

34 United Nations Development Group, The Human Rights Based Approach to Development Cooperation: Towards a Common Understanding Among UN Agencies (New York: UNDG, 2003).

35 See, e.g., International Human Rights Network et al, note 32, 48.

36 UNGPs, note 1, Principle 18 and commentary note the importance of: including all internationally recognized human rights as a reference point; meaningful consultation with potentially affected stakeholders; paying particular attention to vulnerable groups and different risks faced by women and men; drawing on relevant internal and external human rights expertise; and undertaking impact assessment at regular intervals.

37 See UNGPs, note 1, Principles 17-24. See also Office of the United Nations High Commissioner for Human Rights (OHCHR), The Corporate Responsibility to Respect Human Rights: An Interpretive Guide, (New York and Geneva: $\mathrm{UN}, 2012)$.

38 E.g., Desiree Abrahams and Yann Wyss, Guide to Human Rights Impact Assessment and Management (Washington: International Business Leaders Forum, International Finance Corporation and UN Global Compact, 2010); DIHR and IPIECA, note 24; Harrison and Stephenson, note 28; Christina Hill, Women, Communities and Mining: The Gender Impacts of Mining and the Role of Gender Impact Assessment (Melbourne: Oxfam Australia, 2009); Lenzen and d'Engelbronner, note 33; Faris Natour and Jessica Davis Pluess, Conducing an Effective Human Rights Impact Assessment (London: BSR, 2013); Nomogaia, Human Rights Impact Assessment: A Toolkit for Practitioners Conducting Corporate HRIAs (Denver: Nomogaia, 2012); Norwegian Agency for Development Cooperation, Handbook in Human Rights Assessment: State Obligations, Awareness and Empowerment (Oslo: NORAD, 2001); Rights and Democracy, Getting it 
do EIA and SIA (i.e., screening, scoping, baseline, stakeholder engagement, analysis, mitigation, reporting and monitoring). This highlights the potential compatibility of integrating human rights into ESHIA processes. Some of these sources also point to how HRIA differs from other types of assessment, for example by noting the aspects that distinguish what happens in a particular step in HRIA from how this step exists in ESHIA. ${ }^{39}$

Actual examples of HRIAs and the scholarly literature reflecting on such assessments can be identified as a fifth group of resources. In terms of actual examples of HRIA of business activities conducted on a consultancy basis at the site- or project-level, of the few that are in the public domain, the majority are ex-post assessments that analyze the impacts of extractive industries projects. ${ }^{40}$ There are also some examples of reports that present an account of key HRIA findings of a number of assessments at an aggregate level. ${ }^{41}$ Scholarly literature reflecting on HRIA practice provides some insights into the methodologies applied, as well as pointing to some of the key challenges associated with implementing HRIA of business activities. ${ }^{42}$

I considered the above five sets of sources to identify recurring or commonly noted themes and in turn derived the five criteria. In particular, my analysis focused on sources from the first three groups: literature identifying the 'original' or 'essential' elements of HRIA; resources on the human rights-based approach; and the UNGPs. Practical guides on HRIA and examples of HRIA were considered to supplement the analysis, in particular to examine whether (and if so how) the key criteria outlined are reflected in current HRIA practice and any associated challenges. Whilst the sources outlined above provide valuable theoretical and practical insights into HRIA, they are fragmented in the sense that they do not individually present a detailed account of what criteria should guide the further development, implementation and evaluation of HRIA conducted for business activities at the site- or project-level. However, drawing on these sources together, it is possible to identify a number of recurring or commonly noted aspects, related to both content and process, which can therefore be considered essential for HRIA to ensure consistency not only with international human rights standards and principles but also with the expectations set out in the UNGPs. The five key criteria are: ${ }^{43}$

(1) applying international human rights standards - as the benchmark for the assessment, to guide impact identification, analysis, mitigation and remedy;

\footnotetext{
(F'note continued)

Right: A Step-by-step Guide to Assess the Impact of Foreign Investments on Human Rights (Montreal: Rights and Democracy, 2008). It has been pointed out that much of the current guidance remains conceptual and should therefore be reviewed critically and cautiously: Richard Boele and Christine Chrispin, 'What Directions for Human Rights Impact Assessments?' (2013) 31:2 Impact Assessment and Project Appraisal 128, 129.

39 See, e.g., DIHR and IPIECA, note 24; Harrison and Stephenson, note 28.

40 E.g., Brigitte Hamm et al, Human Rights Impact Assessment of the Tampakan Copper-Gold Project (Aachen: MISEREOR and Fastenopfer in collaboration with Bread for All, 2013); LKL International Consulting Inc., Human Rights Impact Assessment of the Bisha Mine in Eritrea (Montreal: LKL International Consulting Inc., 2014); On Common Ground, Human Rights Assessment of Goldcorp's Marlin Mine (Guatemala City: Steering Committee for the Human Rights Assessment of the Marlin Mine, 2010); Mark Wielga et al, Human Rights Impact Assessment on the Proposed Nuiguyo Gold Mine in Indonesia (Denver: Nomogaia, 2009). Not all of these assessments are ex-post.

41 E.g., Tulika Bansal and Yann Wyss, Talking the Human Rights Walk: Nestle's Experience Assessing Human Rights Impacts in its Business Activities (Copenhagen: Danish Institute for Human Rights and Nestle, 2013).

42 See, e.g., Boele and Chrispin, note 38; Kendyl Salcito et al, 'Assessing Human Rights Impacts in Corporate Development Projects' (2013) 42 Environmental Impact Assessment Review 39.

43 I have previously discussed these criteria in a working paper, see note 10.
} 
(2) considering the full scope of impacts - including both actual and potential adverse impacts that are caused by the business, impacts that the business contributes to and impacts directly linked to its operations, products and services through its business relationships;

(3) adopting a human rights-based process - emphasizing the principles of participation and inclusion, equality and non-discrimination, and accountability and transparency;

(4) ensuring accountability - identifying rights-holders and duty-bearers, assigning responsibilities and adequate resources for impact management, including a focus on access to remedy, and making adequate provisions for public reporting; and

(5) addressing impacts according to severity - making sure that assessment of impact severity is guided by human rights considerations and that all identified human rights impacts are effectively addressed.

In the remainder of the article, I will discuss each of these five criteria in turn, detailing what each entails, as well as noting challenges that may be encountered in their implementation in HRIA. For the discussion, I draw on the sources outlined above as well as my personal professional experience, which has included implementing and peer-reviewing HRIAs as well as working on HRIA methodology development for both integrated and stand-alone assessments.

\section{A. Applying International Human Rights Standards}

Human rights are internationally agreed-upon standards and principles and as such, establish an authoritative benchmark for impact identification, analysis, mitigation and remedy. The use of international human rights standards as the benchmark for the implementation of HRIA has the potential to ensure that the coverage of human rights impacts in an assessment is comprehensive. The UNGPs require that the assessment of human rights impacts considers, at a minimum, those rights outlined in the International Bill of Human Rights and those in the Core Labour Conventions of the International Labour Organization, with the consideration of additional human rights standards as appropriate in any given context (e.g., indigenous peoples' rights if they are affected, international humanitarian law in conflict zones). ${ }^{44}$ This does not necessarily mean that all human rights need to be considered to the same level of detail; clearly, it makes sense that an impact assessment focuses on those human rights that are most salient in the given context. However, the approach of screening out rather than screening in specific issues has the potential to avoid the omission of any human rights impacts through requiring the initial consideration of a comprehensive set of human rights, and a considered explanation regarding the subsequent exclusion of any particular topics. ${ }^{45}$ In practice, this approach can lend itself to the inclusion of human rights topics that may be left out in ESHIA or SIA (e.g., workers' rights, security, bribery and corruption), as well as strengthening the focus on topics which may be captured but where enhanced analysis would be beneficial (e.g., gender). ${ }^{46}$

44 UNGPs, note 1, Principle 12.

45 World Bank and Nordic Trust Fund, note 15, 8.

46 See, e.g., Human Rights Council, 'Human Rights Impact Assessments', note 1. 
Grounding an impact assessment in international human rights standards also has the potential to ensure that the information collected for analysis and the benchmark applied for the assessment of impacts are human rights compliant. For example, the legal framework analysis for the impact assessment would include explicit consideration of international human rights standards, including analysis of the degree to which such international standards are reflected in domestic laws and practice in order to facilitate legal enforcement and actual enjoyment of human rights at the national level. The substantive content of human rights is also relevant, i.e., HRIA should be guided by authoritative sources and jurisprudence that elaborate the content of specific human rights. ${ }^{47}$ For example, for economic, social and cultural rights elaborated through the criteria of availability, accessibility, acceptability and quality (AAAQ), HRIA would require systematic consideration of each of these four dimensions in baseline data collection and subsequent evaluation of whether a particular human rights impact has occurred, and if so, the nature of the impact. ${ }^{48}$ Other types of impact assessment that do not have an internationally agreed upon standard or benchmark are likely to present different and inconsistent approaches, not all of which would be compatible with international human rights standards and principles. ${ }^{49}$

Despite the normative authority of international human rights, their legal standing and the evolving development of their precise content, clearly several challenges remain for HRIA. For example, whilst there is a degree of clarity regarding the substantive content of specific rights, this is by no means comprehensive, nor is the domestic (i.e., statelevel) interpretation and implementation of international human rights always consistent (in the case of economic and social and cultural rights also due to the concept of progressive realization $^{50}$ ). As such, context-specific analysis will need to be involved in making the connection between international human rights standards, domestic implementation and rights-holder experiences in a particular HRIA setting. To date, whilst HRIAs frame impacts in human rights language, the extent of legal analysis in terms of precisely how and to what degree a particular human right is impacted appears to remain rather limited. ${ }^{51}$

\section{B. Considering the Full Scope of Impacts}

Drawing on the UNGPs, two key issues can be identified with regard to the scope of impacts to be included in HRIA. Firstly, the inclusion of actual and potential impacts that the business contributes to and that are directly linked to a company's operations, products or services through its business relationships; and secondly, the focus on adverse impacts, as opposed to a focus on both adverse and positive impacts.

47 Harrison, note 9, 110; Salcito et al, note 42, 41; World Bank and Nordic Trust Fund, note 15, 7.

48 On the AAAQ see, e.g., Mads Holst Jensen, Marie Villumsen and Thomas Døcker Petersen, The AAAQ Framework and The Right to Water (Copenhagen: DIHR, 2014). For specific reference to AAAQ in HRIA see, e.g., Salcito et al, note 42,41 and 47.

49 See, e.g., Nora Götzmann et al, 'Social and Human Rights Impact Assessments: What Can They Learn From Each Other?' (2015) 34:1 Impact Assessment and Project Appraisal 14; Harrison, note 9, 110; World Bank and Nordic Trust Fund, note 15, 7.

50 On progressive realization see, e.g., United Nations Economic and Social Council, 'Report of the United Nations High Commissioner for Human Rights', E/2007/82 (25 June 2007).

51 See, e.g., the HRIAs referred to in notes 40 and 41. 


\section{Impacts through Business Relationships}

The UNGPs place significant emphasis on the inclusion of impacts that a business contributes to and that are directly linked to a company's operations, products or services through its business relationships. ${ }^{52}$ In short, the UNGPs require looking beyond the impacts that a business causes: a business should also consider and take responsibility for impacts where it is involved through its business relationships. This requires a shift from scoping the inclusion of impacts according to a 'sphere of influence' analysis. ${ }^{53}$ In short, according to the sphere of influence, those impacts which are the most proximate would be those that are deemed most relevant for the business to address (e.g., impacts on employees or environmental damage on company lands caused by company operations); whereas more remote impacts imply a lower level of company responsibility (e.g., impacts in the supply chain or on downstream communities). Instead, a UNGPs approach establishes responsibility based on 'the company's web of activities and relationships' ${ }^{54}$ Providing that the business causes, contributes to, or is directly linked to, an impact, the business will be considered to have a responsibility to assess and address the impact. In other words, a UNGPs analysis would take all four impacts (on employees, environmental damage, in the supply chain, and on downstream communities), assess the severity of each, and based on this determine any necessary prioritization regarding the timing of implementation of impact mitigation measures. This clear inclusion of impacts that the business contributes to and that are directly linked, and assessing and addressing these impacts based on their severity (as opposed to including and addressing impacts based on considerations of proximity and control), should be a critical feature of HRIA.

The inclusion of impacts to which the business contributes or is directly linked can pose challenges in practice. Companies may raise concerns regarding the assumption of responsibility for impacts that are not associated with a contractual relationship or over which a company has no direct control. For example, in a situation where state security forces are stationed around a company asset and these security forces use excessive force against community protesters, the company may argue that such impacts should not be included in the HRIA, as it cannot take responsibility for addressing adverse impacts caused by state actors. From a UNGPs perspective, however, depending on the precise circumstances this would likely constitute an impact to which the company contributes or is directly linked, and the company would consequently be considered to have a responsibility to address the impact through exercising leverage over the entity in question to change its behaviour. ${ }^{55}$ To strengthen the focus on impacts that the business contributes to or is directly linked to in HRIA practice going forward, it is therefore

\footnotetext{
52 See UNGPs, note 1, Principles 11, 17 and 19. For examples of the different types of impacts see, e.g., OHCHR, note 37, 16-17.

53 'The sphere of influence concept implies that the more control, authority or influence a business has over a situation giving rise to human rights abuses (or the means to improve respect for human rights), the greater the business's responsibility to act.' OHCHR and UN Global Compact cited in Human Rights Council, 'Clarifying the Concepts of "Sphere of Influence" and "Complicity"', A/HRC/8/16 (15 May 2008), note 8 therein.

54 Ibid, 6.

55 UNGPs, note 1, Principle 19 commentary defines leverage: 'Leverage is considered to exist where the enterprise has the ability to effect change in the wrongful practices of an entity that causes harm'.
} 
important that practical, workable and context specific solutions to such impacts are shared widely in the BHR community.

\section{Adverse Impacts and Positive Impacts}

A second key issue relating to scope is that of adverse impacts and positive impacts (or benefits). Human rights due diligence as outlined in the UNGPs focuses explicitly on adverse human rights impacts, rather than on requiring companies to generate or maximize project benefits for impacted workers and communities. By the same token, it is not considered to be acceptable for businesses to offset adverse human rights impacts through positive contributions elsewhere. ${ }^{56}$ This reflects the formulation of the corporate responsibility to respect human rights, as opposed to the state duties to respect, protect and to fulfil human rights.

Making a clear distinction between addressing adverse impacts (avoiding, mitigating and remediating) and generating project benefits (for example, through employment creation, skills transfer or strategic social investment) is important for a number of reasons. Firstly, including both adverse impacts and benefits facilitates a space for the implicit offsetting of adverse impacts. A classic example would be where a company showcases local employment and job creation opportunities as implicitly offsetting adverse impacts caused by business activities, for example human rights impacts on the rights to housing or health associated with in-migration and boomtown effects. Secondly, a human rights perspective emphasizes accountability through the rightsholder and duty-bearer framework. This includes recognizing the complementary yet differentiated duties and responsibilities of state and non-state duty-bearers. Essentially, this is to ensure that the legal obligations of states under international law to respect, protect and fulfil human rights are not reduced through companies assuming the role to protect and to fulfil human rights. Whilst companies may work with state actors to build the capacity of such actors to meet their human rights duties, it is important that this effectively supports, rather than undermines or allows state actors to abdicate, their human rights duties.

In practice, maintaining a strong and clear focus in HRIA on identifying and addressing adverse impacts may present some challenges. For example, there is a high demand from companies to include attention to positive impacts in HRIA. Furthermore, is it possible to always clearly distinguish between an impact mitigation measure and a positive impact in practice? Some HRIA approaches in the BHR field also seem to indicate a preference for the inclusion of both adverse and positive impacts, as long as the HRIA clearly distinguishes between the baseline responsibility to address adverse impacts, and positive impacts. ${ }^{57}$ Lastly, given the growing focus on the private sector in sustainable development, ${ }^{58}$ it appears that the role of business in development will need to be elaborated, and as this happens, what this means for site- or project-level HRIA will also warrant further attention. Whilst these are important considerations, it is arguably

56 UNGPs, note 1, Principle 11 commentary.

57 See, e.g., Natour and Pluess, note 38, 11; Salcito et al, note 42, 40.

58 E.g., United Nations Development Group, Delivering the Post-2015 Development Agenda: Opportunities at the National and Local Levels (New York: UNDG, 2014) 24. 
vital that HRIA of business activities first and foremost ensures a robust focus on addressing adverse human rights impacts.

\section{Adopting a Human Rights-Based Process}

As discussed above, taking a HRBA is central to HRIA. This involves the application of HRBA principles to guide the impact assessment process, specifically the principles of participation and inclusion; equality and non-discrimination; and transparency and accountability. ${ }^{59}$

\section{Participation and Inclusion}

From a human rights perspective, the principle of inclusive participation 'goes well beyond mere consultation or a technical add-on to project design' ${ }^{60}$ It is a fundamental principle of democracy that people are entitled to participate in decisions that affect them. Applying this understanding of participation in a HRIA context would require that rights-holders are enabled to meaningfully take part in shaping and influencing the assessment process itself, as well as impact-related findings and decisions. The limitations associated with how consultation and participation in impact assessment processes are often actually conducted have been pointed out by scholars and practitioners. For example, it has been noted that consultation often occurs when critical decisions have already been made. ${ }^{61}$ Furthermore, it has been found that consultation processes often remain company driven, with the result that communities are placed in the position of responding to information provided to them rather than consultations providing opportunities for more collaborative information and knowledge sharing, and decision-making. ${ }^{62}$ For developing HRIA practice, this suggests a need to pay greater attention to the involvement of rights-holders in scoping, development of terms of reference for impact assessment, and the design, implementation and monitoring of impact mitigation measures. In other words, rather than stakeholder consultation being just one of the impact assessment stages, HRIA needs to make provisions for the inclusive participation of rights-holders at critical points throughout the whole assessment process.

Working with the principles of participation and inclusion in HRIA also calls for the careful consideration of the power-dynamics at play within communities, between rights-holders, companies and state actors, as well as with regard to the persons comprising the assessment team. With a few exceptions, such considerations are notably absent in current literature and guidance on HRIA. ${ }^{63}$ Overall, the often vast disparities in

\footnotetext{
59 The HRBA principles also include universality and inalienability, indivisibility, interdependence and interrelatedness, all of which are relevant when using international human rights standards as a benchmark for impact assessment. However, in this section I have chosen to focus on those HRBA principles that speak most clearly to process.

60 OHCHR, note 32, 26.

61 E.g., Harrison, note 9, 114. For critiques in the SIA context see, e.g., Janette Harz-Karp and Jenny Pope, 'Enhancing Effectiveness through Deliberative Democracy' in Frank Vanclay and Ana Maria Esteves (eds.), New Directions in Social Impact Assessment (Cheltenham: Edward Elgar, 2011) 253, 254; Frank Vanclay and Ana Maria Esteves, 'Current Issues and Trends in Social Impact Assessment' in Frank Vanclay and Ana Maria Esteves (eds.), New Directions in Social Impact Assessment (Cheltenham: Edward Elgar, 2011) 3, 14.

62 E.g., Harz-Karp and Pope, note 61, 254-5.

63 See, e.g., World Bank and Nordic Trust Fund, note 15, 10, noting that in the context of government or company HRIA there is a risk that the political or economic interests of the proposed intervention may unduly influence the analysis, conclusions or recommendations of the HRIA.
} 
power between companies and communities is not explicitly identified, discussed or problematized. What do power-dynamics mean for the very concept and practice of HRIA in a BHR context? Can HRIA facilitate the building of rights-holder capacity to know and claim their human rights in a meaningful way? Will HRIA increase existing divisions within communities or even create new divisions? ${ }^{64}$ Recognition of powerdynamics and distribution of power is a fundamental component of a HRBA. ${ }^{65}$ Human rights due diligence as elaborated in the UNGPs, however, is a management tool designed for companies; it is not a tool designed for rights-holders or rights-holders' representatives. As such, on the one hand it is arguable that HRIA conducted on a consultancy basis for companies per se precludes the adoption of fully participatory approaches that facilitate community empowerment envisaged from a HRBA perspective (at least as long as HRIA remains as closely bound by project riskmanagement considerations as it currently is). On the other hand, it might be argued that opportunities do exist in HRIA for recognizing and reconfiguring power relations and creating meaningful participation, for example, by adopting or merging with community-based HRIA approaches. As HRIA methodologies and practice are developed further, this seems to be an obvious and important space for further investigation. At the very least, business and human rights practitioners working in the area of HRIA should take steps to deepen the understanding of power-dynamics in HRIA, including analysis of the implications that the power relations in a given context have for the participation and inclusion of impacted workers and community members in the impact assessment.

\section{Equality and Non-discrimination}

Non-discrimination is a core tenet of the international human rights framework and a HRBA. $^{66}$ In a HRIA context, paying particular attention to equality and nondiscrimination involves understanding structural discrimination in communities and societies, disaggregated stakeholder analysis, as well as being cognizant of the disproportional distribution of impacts and benefits. At the most basic level, it requires an understanding of communities, and abandoning any ideas or conceptions about the impacted community as a homogenous entity, that is, an understanding of 'the specific impacts on specific people' rather than focusing on aggregate social welfare. ${ }^{67}$

Ensuring a comprehensive approach to equality and non-discrimination in HRIA would also involve identifying, understanding and respecting the human rights attributed to particular groups of rights-holders that are affected. With regard to gender, for example, the UNGPs call for specific attention to the differential experience of impacts by women and men, and note the role of sex-disaggregated data for informing such analysis. ${ }^{68}$ In HRIA, this would include consideration of the roles of women and men in

\footnotetext{
64 Oxfam America and Rights and Democracy, note 26, 5.

65 E.g., Cornwall and Nyamu-Musembi, note 32, 1432.

66 See, e.g., International Human Rights Network et al, note 32; OHCHR, note 32.

67 UNGPs, note 1, Principle 18 commentary. See also Götzmann et al, note 49; Harrison, note 16.

68 Ibid, Principles 18 and 20. The UN Working Group on Business and Human Rights is also required to integrate a gender perspective in implementing its mandate: Human Rights Council, note 2.
} 
family, work and social structures in communities; intersectionality analysis to provide an understanding of differences between women based on factors such as age, race or ethnicity; ${ }^{69}$ and incorporating this analysis in identifying and addressing human rights impacts. A thorough gender analysis from a human rights perspective would involve a shift in how certain impacts on women and girls are recognized and addressed. For example, increases in underage prostitution due to the influx of contract workers would not be construed as merely a health issue for the girls and contract workers (which is managed by keeping the contract workers in secure camps and running a sexual health education programme) but also recognized as an impact on the girls' right to physical integrity and the right to freedom from the worst forms of child labour.

In addition to considering the human rights of specific rights-holders, applying the principle of non-discrimination in HRIA requires contextual analysis to identify those who may be vulnerable or marginalized in a particular project setting. Currently, there is a shift in impact assessment from focusing on predetermined vulnerable groups (i.e., considering indigenous peoples, women, or children to be vulnerable per se) to more nuanced understandings of vulnerability based on analysis of contextual circumstances. ${ }^{70}$ Incidentally, this represents a shift away from seeing groups of indigenous peoples, women, children or others, as homogenous groups within communities. As practice is developed further, it will be important to see to how such more nuanced analyses can be effectively embedded in HRIA to better understand and address the impacts experienced by vulnerable or marginalized workers and community members.

\section{Transparency and Accountability}

The purpose of transparency in the context of process is to enable rights-holders to access and understand information in order that they can be meaningfully involved in decisionmaking that affects them. ${ }^{71}$ The importance of access to information in an impact assessment context can be identified in a number of international instruments as well as the emerging literature and guidance on HRIA specifically. ${ }^{72}$ Transparency relates to both the information about the project being assessed (and the timeliness) as well as information about the HRIA process itself. ${ }^{73}$ For example, disclosure around terms of reference, scoping studies and impact management plans should be integral to HRIA to enable rights-holder participation in shaping these, as well as to facilitate holding companies to account for effectively addressing the impacts that have been identified. Consideration of rights-holder capacity to engage with impact assessment information needs to be a

\footnotetext{
69 For elaboration of intersectionality see, e.g., Kimberle Crenshaw, 'Mapping the Margins: Intersectionality, Identity Politics, and Violence against Women of Color' (1991) 43:6 Stanford Law Review 1241.

70 See, e.g., European Investment Bank, Environmental and Social Handbook (Luxemburg: European Investment Bank, 2013) 63. Vulnerability analysis has been applied in the development field for some time. See, e.g., Johannes Hoogeveen et al, A Guide to the Analysis of Risk, Vulnerability and Vulnerable Groups (Washington: World Bank, 2005), http://siteresources.worldbank.org/INTSRM/Publications/20316319/RVA.pdf (accessed 17 August 2016).

71 See, e.g., International Human Rights Network et al, note 32, 68; OHCHR, note 32, 16 and 27.

72 See, e.g., Harrison, note 9, 113; Lenzen and d'Engelbronner, note 33, 9; United Nations Economic Commission for Europe, Convention on Access to Information, Public Participation and Access to Justice in Environmental Matters (Aarhus: UNECE, 1998); World Bank and Nordic Trust Fund, note 15, 16-17.

73 Harrison, note 16, 6; Oxfam America and Rights and Democracy, note 26, 8; World Bank and Nordic Trust Fund, note 15,16 .
} 
key consideration. For instance, the impact assessment process should make provision for capacity building - to be carried out by an independent third party - as necessary to enable workers and community members to meaningfully participate in the HRIA.

\section{Ensuring Accountability}

The ability of rights-holders to claim their rights, and duty-bearers to correspondingly uphold these rights, is a fundamental aspect of international human rights law and a HRBA. In a HRIA context, this highlights the need for the recognition of impacted individuals as rights-holders and the corresponding acknowledgment of companies' responsibilities for impact management; attention to access to remedy; and impact assessment reporting.

\section{Rights-holders and Duty-bearers}

Introducing the concept of rights-holders into stakeholder analysis enables the recognition of impacted communities, or project-affected people, as people with legal entitlements and active agents in decision-making, rather than as (passive) individuals who are affected by a project. Stakeholders are usually defined as those who are impacted by a project or can potentially influence a project. ${ }^{74}$ In practice, this has the risk for impact assessment engagement to prioritize the concerns of vocal and powerful individuals or organizations, rather than focusing on those who are experiencing adverse human rights impacts. In particular, those rights-holders who are vulnerable or marginalized may receive inadequate attention. The recognition of impacted individuals as rights-holders in stakeholder mapping, analysis and engagement does not mean that rights-holders are the only relevant stakeholders. However, it does imply paying greater attention to those workers and community members who experience adverse human rights impacts, irrespective of how vocal they may be in articulating these impacts.

Identifying rights-holders and duty-bearers in stakeholder analysis also supports an emphasis on the accountability of duty-bearers for addressing identified impacts. With the endorsement of the UNGPs by the Human Rights Council in 2011, the corporate responsibility to respect human rights has become 'a global standard of expected conduct for all business enterprises wherever they operate. It exists independently of States' abilities and/or willingness to fulfil their own human rights obligations, and does not diminish those obligations' ${ }^{75}$ As such, the UNGPs recognize the duties of states and the responsibilities of businesses vis-à-vis human rights as differentiated but complementary.

Focusing on companies' responsibilities to identify and address their human rights impacts entails an emphasis on the assignment of organizational resources for HRIA and impact management. Without sufficient resources, including human resources and skills,

74 Note that in the context of the UNGPs, the OHCHR proposes a definition which has an increased focus on individuals and communities who are impacted by elaborating the definition of stakeholder with a narrower definition of affected stakeholder: 'A stakeholder refers to any individual who may affect or be affected by an organization's activities. An affected stakeholder refers here specifically to an individual whose human rights have been affected by an enterprise's operations, products or services.' OHCHR, note 37,8 .

75 UNGPs, note 1, Principle 11 commentary. 
time and financial resources, the very notion of meeting the corporate responsibility to respect is undermined. Despite the growing attention to human rights by businesses, however, the level of resourcing for implementing human rights due diligence frequently remains poor, compared to the level of resources that are invested into, for example, technical operations, health and safety or even environmental management. Often within companies, assignment of human rights responsibilities remains marginalized compared to more 'standard' business functions, such as human resources, procurement, security management and so forth. ${ }^{76}$ As such, dedication of additional resources by companies to human rights impact management appears to be an essential step to enable greater accountability for addressing human rights impacts. Another critical component to improve accountability is consideration of human resources and staff capacity. Literature on HRIA has suggested that the very exercise of undertaking HRIA can be beneficial for increasing organizational understanding of human rights impacts and embedding accountability for managing these, for example, by working across different business unit functions that may not have previously identified human rights as relevant to their area of work and responsibilities. ${ }^{77}$ To challenge the marginalization of human rights in corporate settings and to increase accountability of companies for identifying and addressing human rights impacts, it is therefore essential that HRIA includes attention to integrating responsibilities for human rights impact management across different organizational functions. Moreover, HRIA should be seen to function as a forum for dialogue and human rights education.

The rights-holder and duty-bearer framework may also usefully inform how state duty-bearers and any associated impacts are dealt with in HRIA. In international human rights law, state actors remain the primary duty-bearers, having the duties to respect, protect and fulfil human rights. In a HRIA context, this raises practical questions about how impacts associated with state actors should be dealt with or how state actors might be involved in impact mitigation and management. Given that state actors are the primary human rights duty-bearers, how they are engaged in HRIA should be a key consideration in practice going forward. ${ }^{78}$

\section{Access to Remedy}

In international human rights law, duty-bearers have the obligation to provide effective remedies to individuals for human rights breaches. ${ }^{79}$ Access to remedy is also the third pillar of the UNGPs, which addresses both judicial and non-judicial avenues. ${ }^{80}$ It is therefore important that HRIA includes explicit consideration of access to remedy, both during the process of an assessment as well as with regard to the findings. For example, legal framework analysis should include a focus on the availability and effectiveness of judicial remedies for business-related human rights abuses (including consideration of any barriers for victims of human rights abuses to access to remedy) to provide an

\footnotetext{
76 Compare Deanna Kemp and John Owen, 'Community Relations in Mining: Core to Business but not "Core Business"' (2013) 38 Resources Policy 523, making a similar argument regarding community relations in mining.

77 See, e.g., Bansal and Wyss, note 41, 9; Boele and Crispin, note 38, 132; Lenzen and d'Engelbronner, note 33, 10; Natour and Pluess, note 38, 11.

78 Bansal and Wyss, note 41, 25; World Bank and Nordic Trust Fund, note 15, 18.

79 See, e.g., Universal Declaration of Human Rights, UN Doc A/810 (adopted on 10 December 1948), Article 8.

80 UNGPs, note 1, Principles 25-31.
} 
understanding of the extent to which impacted individuals are able to make human rights-based claims via judicial mechanisms. Where adverse impacts identified constitute a breach of human rights standards, it is important that the HRIA process enables the referral of such impacts to the appropriate judicial channels, providing this is in accordance with the wishes of the rights-holder(s) involved.

In addition, operational-level grievance resolution should be available throughout an impact assessment process, as well as throughout the project lifecycle, to capture any shortcomings in impact identification and mitigation, including new issues arising. Operational-level grievance mechanisms are an integral part of human rights due diligence and companies are expected to participate in or establish such mechanisms as a source of access to remedy and early warning system for human rights abuses. ${ }^{81}$ Since the Human Rights Council's approval of the 'Protect, Respect and Remedy' Framework and subsequent endorsement of the UNGPs, many companies have developed and implemented non-judicial operational-level grievance mechanisms and there are numerous industry-level guides for the development of such mechanisms. ${ }^{82}$ However, it is not always clear how operational-level grievance mechanisms relate to HRIA. As such, it may be useful to consider how the two can be more effectively linked, to ensure that adverse impacts identified through operational-level grievance mechanisms feed into HRIA and vice versa (that is, impacts identified in HRIA inform the development and implementation of operational-level grievance mechanisms). This being said, it is important to ensure that operational-level grievance mechanisms do not interfere with rights-holders' access to judicial mechanisms for human rights abuses. ${ }^{83}$

\section{Transparency and Formal Reporting}

Transparency is also relevant in the context of the disclosure of formal and public impact assessment reporting. The UNGPs indicate that formal reporting on due diligence is required in cases of severe human rights abuses, with provisos for rights-holder safety and legitimate requirements of commercial confidentiality. ${ }^{84}$ Literature and guidance on HRIA make the case for public reporting on HRIA methodology, processes and findings more strongly, suggesting that this is essential to, 'monitor the accuracy, independence and legitimacy of the entire exercise', 85 and that 'ultimately, there is no way in which individual assessments can be scrutinized and strong assessments distinguished from weaker ones without the methodology and the results being made publicly available'. ${ }^{86}$ As such, the presumption should be towards full disclosure and any exemptions narrowly defined and clearly justified, with the proviso that information disclosure does not cause harm (or risks of harm) to the rights-holders involved. ${ }^{87}$

\footnotetext{
81 Ibid, Principles 22, 29 and 31.

82 E.g., International Council on Mining and Metals, Human Rights in the Metals and Mining Industry: Handling and Resolving Local Level Concerns and Grievances (London: ICMM, 2009).

83 UNGPs, note 1, Principle 29 commentary.

84 Ibid, Principle 21 and commentary.

85 World Bank and Nordic Trust Fund, note 15, 17.

86 Harrison, note $9,113$.

87 Ibid, 112; Oxfam America and Rights and Democracy, note 26, 8; World Bank and Nordic Trust Fund, note 15, 17.
} 
BHR practitioners may be confronted with company hesitations regarding public reporting of HRIA. For example, companies may express concerns about publishing impact assessment findings that may be perceived as critical of the state, or contain information that may give rise to legal liability claims. ${ }^{88}$ However, it has also been suggested that if a company undertakes a HRIA without disclosing such findings, stakeholders will suspect inaccuracies or lack of transparency and as a result the company will suffer. ${ }^{89}$ Whilst concerns regarding reporting both from a business and a rights-holder safety perspective are a reality, these are surely not insurmountable, contrary to how these are often presented by companies. For example, detailed direct reporting back to the rights-holders and other stakeholders involved in an assessment could be combined with a published summary report of the impact assessment, or it may be possible to work towards greater disclosure of HRIA methodology and findings through a step-by-step process. ${ }^{90}$

Given that HRIA in the BHR field is an emerging practice, it is vital to ensure that more examples of HRIAs are made publicly available and more spaces for exchange about HRIA are created. Without this, practice will not be subject to the scrutiny that is required to ensure that HRIA is consistent with international human rights standards and principles and that it actually contributes to identifying and addressing the adverse impacts of business activities on the human rights enjoyment of workers and community members. 91

\section{E. Addressing Impacts According to Severity}

The UNGPs state that human rights impacts should be assessed according to their severity and that all human rights impacts identified in an assessment must be addressed. ${ }^{92}$ It is therefore relevant to consider what is meant by impact severity, as well as how the actions to address human rights impacts are to be developed and prioritized.

\section{Assessment of Impact Severity}

According to the UNGPs, impact severity should be assessed by considering the 'scope, extent and irremediability' of the impacts. ${ }^{93}$ Notably, the UNGPs adopt the terminology of severity rather than significance. Significance involves combining consideration of the magnitude (or severity) of an impact with the factor of likelihood to determine significance. ${ }^{94}$ The key difference in a UNGPs approach is that assessing severity does not involve the consideration of likelihood (although likelihood does become relevant for the purpose of prioritizing actions to address impacts that are of the same severity). ${ }^{95}$

\footnotetext{
88 Bansal and Wyss, note 41, 25; Natour and Pluess, note 38, 15.

89 E.g., Tarek F Maassarani et al, 'Extracting Corporate Responsibility: Towards a Human Rights Impact Assessment' (2007) 40:1 Cornell International Law Journal 135, 167.

90 See, e.g., Bansal and Wyss, note 41, 35; Natour and Pluess, note 38, 15.

91 Boele and Crispin, note 38, 129; Harrison and Stephenson, note 28, 32.

92 UNGPs, note 1, Principles 14 and 24, and commentary.

93 Ibid, Principle 14 commentary.

94 See, e.g., Vanclay et al, note 5, 49.

95 See UNGPs, note 1, Principle 29 and commentary.
} 
In practice, a focus on severity can result in greater attention being paid to those impacts which might be severe if they were to occur, even if the likelihood is low. This is consistent with the UNGPs approach of taking a risk to rights-holder rather than a risk to business perspective.

Consistent with the above discussion on participation and inclusion, the involvement of rights-holders in analysing impacts and determining their severity also needs to be ensured. This will require more than a mere validation of impact assessment findings: the process should extend to considering how to involve rights-holders in the analysis of impact severity and facilitating assessment of impact severity from the point of view of the individuals who are impacted. Consideration of the interrelatedness of human rights (as well as between environmental, social and human rights impacts) is also relevant, as the concept of severity 'is not absolute but relative to the other human rights impacts that have been identified'. 96

\section{Developing and Prioritizing Actions to Address Impacts}

The UNGPs emphasize that all identified human rights impacts must be addressed. ${ }^{97}$ This includes impacts that the business causes, contributes to and impacts that are directly linked to operations, products or services through its business relationships. The UNGPs add the proviso that in those cases where it is not possible to address all human rights impacts simultaneously, it is permissible to prioritize the implementation of mitigation measures based on the severity of the identified impacts, that is, to first prevent and mitigate those impacts that are most severe or where a delayed response would make them irremediable. ${ }^{98}$

It cannot be overstated that the starting premise is that all impacts must be addressed, and that prioritization is only relevant for the purposes of determining which impacts to address first. However, in practice, BHR practitioners may face challenges in balancing a holistic approach that pays particular attention to qualitative data and duly considers all impacts, whilst at the same time trying to create buy-in from a company for the effective implementation of mitigation measures and impact management plans. For example, it has been noted that companies may be more responsive to quantitative data scoring to prioritize mitigation actions than qualitative narrative descriptions. ${ }^{99}$ However, from a human rights perspective, paying increased attention to such qualitative analysis may be precisely what is necessary for effectively assessing and addressing human rights impacts. Furthermore, if HRIAs are to provide robust and evidence-based approaches to assessing and addressing impacts, it will be necessary to integrate human rights indicators in impact management. Whilst there has been much work done by UN agencies to develop both quantitative and qualitative indicators to assess and monitor human rights enjoyment, it has been pointed out that to date 'there is little evidence of their active use in the majority of existing assessments'. ${ }^{100}$

\footnotetext{
96 Ibid, note 1, Principle 24 commentary.

97 Ibid.

98 Ibid. See also OHCHR, note 37, 82-4.

99 Salcito et al, note $42,43$.

100 Harrison, note 9, 110.
} 


\section{Conclusion}

In this article, I have considered the emerging practice of HRIA in the field of BHR. Whilst the assessment of human rights impacts of business activities has gained significant attention in recent years, not least in light of the UNGPs, current HRIA approaches vary considerably indicating a lack of common understanding in the BHR community as to what precisely a good practice HRIA should entail. Moreover, the extent to which such assessments in fact facilitate processes and outcomes that effectively address the adverse human rights impacts of business activities remains largely unknown. This can be problematic from the perspective of impact assessment practitioners, rights-holder as well as businesses, as it is not always clear what parameters are to be considered when commissioning, undertaking, participating in, or evaluating such assessments, to ensure that these meaningfully contribute to preventing and addressing the adverse human rights impacts of business activities. Furthermore, there is limited scholarly literature on HRIA in the BHR field, which might usefully contribute to the development and evaluation of HRIA methodologies and practice.

In order to fill this gap in the existing literature, I have proposed the following five criteria which should underpin the methodologies used to assess the human rights impacts of business activities: (1) applying international human rights standards; (2) considering the full scope of impacts; (3) adopting a human rights-based process; (4) ensuring accountability; and (5) addressing human rights impacts according to severity. I have argued that these criteria can provide useful parameters to guide the development, implementation and evaluation of HRIA methodologies and practice going forward to ensure that these are consistent with international human rights standards and principles as well as the expectations set out in the UNGPs. I posit that such consistency and alignment will increase the likelihood of generating HRIA practice that meaningfully contributes to preventing and addressing adverse business-related human rights impacts. This proposition will of course require testing, through further empirical research and scholarly enquiry into emerging HRIA approaches.

If HRIA in the BHR field has to provide the 'value added' that is sometimes ascribed to it, it seems essential that the evolving methodologies and practice are subject to further scrutiny, evaluation, dialogue and debate, including scholarly enquiry. It is only through such dialogue and enquiry that it will be possible to better define what constitutes good practice HRIA, consider precisely what purpose it can serve in a BHR context, and understand how it can be effectively implemented to ensure actual and meaningful outcomes for rights-holders and other stakeholders. The current absence of publicly available assessments and methodologies, as well as limited fora where practitioners, companies, workers, community members and other stakeholders can share experiences, including both challenges and good practices, poses a major obstacle to improving practice in the area of HRIA. As such, the potential of HRIA to contribute to enhancing the accountability of businesses for preventing and addressing adverse human rights impacts also warrants further investigation. At the site- or project-level, such enquiry might take the form of empirical research into questions such as: Are HRIA recommendations implemented and do they effectively address the human rights impacts that were identified? How do HRIAs influence project decision-making, for 
example by influencing project design, operations or closure? Do HRIAs strengthen advocacy possibilities for communities and civil society, and if so how? At a broader level, further research might look into: How can developing HRIA practice connect to and inform regulatory developments, such as by strengthening existing provisions for social impact assessment or by contributing to the establishment of legislative provisions for HRIA? What role might HRIA provisions in industry standards play, for example by allowing for deeper specificity of HRIA practice that is responsive to industry context? How can HRIA provisions in the performance standards of project finance providers be effectively enacted and implemented, including by making use of associated monitoring and enforcement mechanisms?

By drawing out key content and process elements that have been identified as necessary for HRIA in existing literature and guidance, the five criteria proposed in this article could provide a framework through which to undertake such further analysis and enquiry. A further area for attention may be to consider the potential connections between HRIA carried out for companies on a consultancy basis and the methodologies and practice developed in the area of community-based HRIA. In keeping with the focus on rights-holders and taking a HRBA to impact assessment, how these methodologies might inform and learn from each other - in particular in terms of recognizing, analyzing and potentially reconfiguring the power relations at play in particular project contexts would benefit from further investigation. 